\title{
Correction to: Hepatobiliary disease in XLMTM: a common comorbidity with potential impact on treatment strategies
}

\author{
Adele D’Amico ${ }^{1,2^{*}} \mathbb{0}$, Antonella Longo ${ }^{2}$, Fabiana Fattori ${ }^{1}$, Michele Tosi ${ }^{5}$, Luca Bosco ${ }^{2}$, \\ Maria Beatrice Chiarini Testa ${ }^{3}$, Maria Giovanna Paglietti ${ }^{3}$, Claudio Cherchi $^{3}$, Adelina Carlesii ${ }^{4}$, Irene Mizzoni ${ }^{1,2}$ and \\ Enrico Bertini ${ }^{1}$
}

\section{Correction to: Orphanet J Rare Dis (2021) 16:425}

https://doi.org/10.1186/s13023-021-02055-1

Following publication of the original article [1], the authors reported that the given name of Maria was omitted from the author group. The given name has been added to the author group and is presented correctly in this correction article.

The incorrect author name is: Giovanna Paglietti.

The correct author name is: Maria Giovanna Paglietti.

The original article [1] has been corrected.

\section{Author details}

${ }^{1}$ Unit of Muscular and Neurodegenerative Disorders, Genetics and Rare Diseases Research Division, Department of Neurosciences, Bambino Gesù Children's Hospital, IRCCS, piazza S. Onofrio 4, 00165 Rome, Italy. ${ }^{2}$ Genetics and Rare Diseases Research Division, Bambino Gesù Children's Hospital, IRCCS, Rome, Italy. ${ }^{3}$ Pneumology Unit, University Hospital Pediatric Department, Bambino Gesù Children's Hospital, IRCCS, Rome, Italy. ${ }^{4}$ Unit of Neurorehabilitation, Department of Neuroscience, IRCCS Bambino Gesù Children's Hospital, Rome, Italy. ${ }^{5}$ Unit of Child Neurology and Psychiatry, Tor Vergata University Hospital, Rome, Italy.

Published online: 17 January 2022

\author{
Reference \\ 1. D'Amico et al. Orphanet J Rare Dis (2021) Hepatobiliary disease in XLMTM: \\ a common comorbidity with potential impact on treatment strategies \\ (2021) 16:425. https://doi.org/10.1186/s13023-021-02055-1
}

\section{Publisher's Note}

Springer Nature remains neutral with regard to jurisdictional claims in published maps and institutional affiliations.

*Correspondence: adele2.damico@opbg.net

1 Unit of Muscular and Neurodegenerative Disorders, Genetics and Rare Diseases Research Division, Department of Neurosciences, Bambino Gesù Children's Hospital, IRCCS, piazza S. Onofrio 4, 00165 Rome, Italy

Full list of author information is available at the end of the article

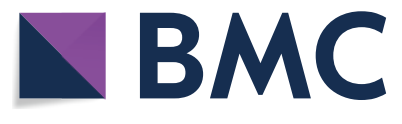

(c) The Author(s) 2021. Open Access This article is licensed under a Creative Commons Attribution 4.0 International License, which permits use, sharing, adaptation, distribution and reproduction in any medium or format, as long as you give appropriate credit to the original author(s) and the source, provide a link to the Creative Commons licence, and indicate if changes were made. The images or other third party material in this article are included in the article's Creative Commons licence, unless indicated otherwise in a credit line to the material. If material is not included in the article's Creative Commons licence and your intended use is not permitted by statutory regulation or exceeds the permitted use, you will need to obtain permission directly from the copyright holder. To view a copy of this licence, visit http://creativecommons.org/licenses/by/4.0/. The Creative Commons Public Domain Dedication waiver (http://creativecommons.org/publicdomain/zero/1.0/) applies to the data made available in this article, unless otherwise stated in a credit line to the data. 